\title{
Synthesis of 6-Adamantyl-2-pyridone and Reversible Hydrogen Activation by the Corresponding Bis(perfluorophenyl)borane Complex
}

\author{
Felix Wech ${ }^{\mathrm{a}}$ \\ Tizian Müller ${ }^{\mathbf{a}}$ \\ Jonathan Becker ${ }^{\mathrm{b}}$ \\ Urs Gellrich*a (i) \\ a Institut für Organische Chemie, Justus-Liebig-Universität \\ Gießen, Heinrich-Buff-Ring 17, 35392 Gießen, Germany \\ urs.gellrich@org.chemie.uni-giessen.de \\ b Institut für Anorganische und Analytische Chemie, Justus-Liebig- \\ Universität Gießen, Heinrich-Buff-Ring 17, 35392 Gießen, \\ Germany
}
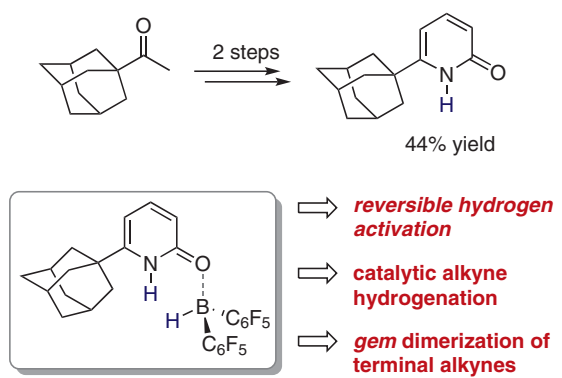

activations with terminal alkynes. ${ }^{5}$ Likewise, pyridonate borane 1a reacts with terminal alkynes to give a pyridone alkynyl borane complex $\mathbf{5}$.

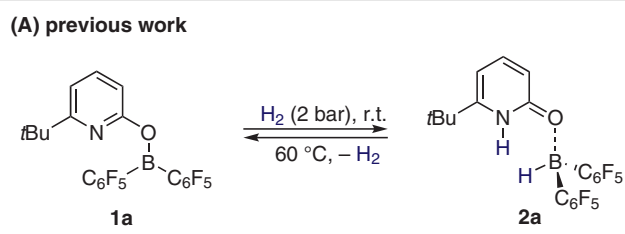

(B) this work

Key words frustrated Lewis Pair, hydrogen activation, pyridones, boron-ligand cooperation, DFT

In 2006, Stephan and co-workers reported the seminal finding that specific combinations of sterically encumbered Lewis bases and highly Lewis acidic boranes are able to activate dihydrogen. ${ }^{1}$ The unique reactivity of these Lewis pairs was attributed to the fact that they do not form classic Lewis adducts. Therefore, the term frustrated Lewis pairs (FLP) was coined to describe these reactive Lewis pairs. ${ }^{2} \mathrm{Re}-$ cently, we reported the reversible activation of dihydrogen by the pyridonate borane 1a, that can be described as an intramolecular FLP (Scheme 1). ${ }^{3}$ A characteristic aspect of hydrogen activation by $\mathbf{1} \mathbf{a}$ is that the covalently bound pyridonate substituent becomes a datively bound pyridone ligand upon bond activation. This change in the coordination sphere of the borane is reminiscent of metal-ligand cooperation and was therefore referred to as boron-ligand cooperation. ${ }^{4}$ This mode of action allows $2 \mathrm{a}$ to dissociate into 6tert-butyl-2-pyridone and $\mathrm{HB}\left(\mathrm{C}_{6} \mathrm{~F}_{5}\right)_{2}$ (Piers' borane). This dissociation enables the hydroboration of an alkyne. A subsequent protodeborylation yields the corresponding cis alkene and regenerates the pyridonate borane 1a. In this way, the catalytic semi-hydrogenation of alkynes was realized (Scheme 2). ${ }^{4}$ Classic FLPs undergo irreversible $\mathrm{C}_{\mathrm{sp}}-\mathrm{H}$

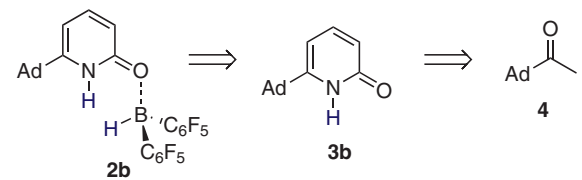

Scheme 1 (A) Reversible hydrogen activation by a 6-tert-butyl-2-pyridonate borane 1a described previously. (B) A working hypothesis of the research project described herein: Synthesis of 6-adamantyl-2-pyridone borane complex and reversible hydrogen activation by a corresponding pyridonate borane $(\mathrm{Ad}=$ adamantyl).

However, we were able to show that $\mathrm{C}_{\mathrm{sp}}-\mathrm{H}$ activation of terminal alkynes by $\mathbf{1 a}$ is reversible and thus competes with dihydrogen activation. Therefore, we were able to realize the first metal-free semi-hydrogenation of terminal alkynes (Scheme 2, bottom). ${ }^{6}$ In the absence of $\mathrm{H}_{2}$, the alkynyl borane complex formed upon $\mathrm{C}_{\mathrm{sp}}-\mathrm{H}$ activation reacts at elevated temperatures with a second equivalent of the alkyne to yield the gem-dimerization product of the terminal alkyne (Scheme 2, top). This reaction regenerates 1a (Scheme 2). ${ }^{7}$ Thus, we were able to devise a protocol for the metal-free dimerization of terminal alkynes catalyzed by 1a. The tert-butyl group at the 6-position of the pyridine ring is required to suppress the dimerization of $\mathbf{1 a}$. Thus we 
became interested in how the replacement of this tert-butyl group by a sterically more demanding and electron-rich adamantyl group would affect the properties of the pyridonate borane (Scheme 1 ).

To synthesize the required 6-adamantyl-2-pyridone $\mathbf{3 b}$, we followed a procedure of Hintermann and co-workers that we had successfully applied for the synthesis of $\mathbf{1 a}{ }^{8}$ We first prepared the sodium enolate $\mathbf{6}$ from commercially available 1-acetyladamantane (4) (Scheme 3). Next, the enolate 6 was used to generate a phosphonium ylide in situ from the phosphonium salt $\mathbf{7}$ to initiate a Wittig olefination. The addition of acetic acid enabled the condensation that furnished the adamantyl pyridone $\mathbf{3 b}$ in 52\% yield (Scheme 3). Single-crystal X-ray diffraction (SCXRD) analysis revealed that $\mathbf{3 b}$ crystallizes as a lactam dimer in the space group $P \overline{1}$ (Figure 1 ).

\section{Biographical Sketches}
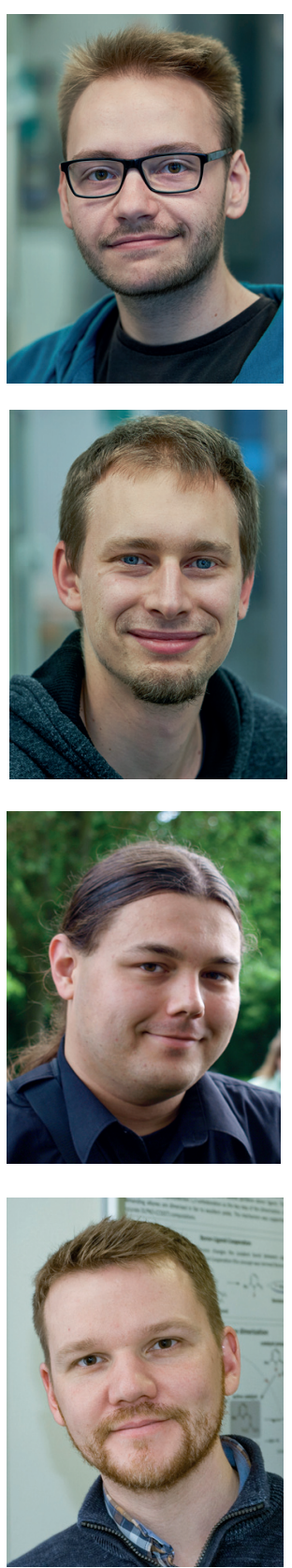

Felix Wech studied chemistry at Justus-Liebig-Universität Gießen and obtained his B.Sc. in 2017. He then joined the research group of Dr. Urs Gellrich for an internship in 2019 and obtained his M.Sc. in 2020 for his work on the pyridone-borane-catalyzed hydrogenations of alkynes. Currently, he is a doctoral student in the group of Urs Gellrich, investigating the application of pyridine-borane complexes for metal-free catalysis.

gen through self-association of frustrated Lewis pairs, both experimentally and computationally.
Gießen and received his B.Sc. in 2016. He joined the research
Jonathan Becker studied chemistry at Justus-Liebig-Universität Gießen and received a 'Dr. rer. Nat' degree working in the group of Professor Siegfried Schindler. He then worked as a

Urs Gellrich studied chemistry at the University of Freiburg in Germany where he obtained his doctorate in 2013 for his work on supramolecular ligands under the guidance of Prof. Bernhard Breit. In 2014, he moved to Israel and joined the group of Prof. David Milstein at the postdoctoral fellow with Dr. Peter Müller at the Massachusetts Institute of Technology (USA). After returning to Germany and Justus-Liebig-Universität Gießen, he now works on crystallo- graphic problems in the group of Professor Müller-Buschbaum at the Institute of Inorganic and Analytical Chemistry.
Weizmann Institute of Science as a postdoctoral researcher. In 2017, Urs started his independent career as a Liebig Fellow of the Fonds der Chemischen Industrie (FCI) at Justus-Liebig-Universität Gießen, where he is currently an Emmy Noether Group Leader. His research fo- cuses on the in silico design of novel metal-free systems for bond activation and catalysis. For his work on the concept of boron-ligand cooperation, he was awarded the ADUC Prize in 2020. 


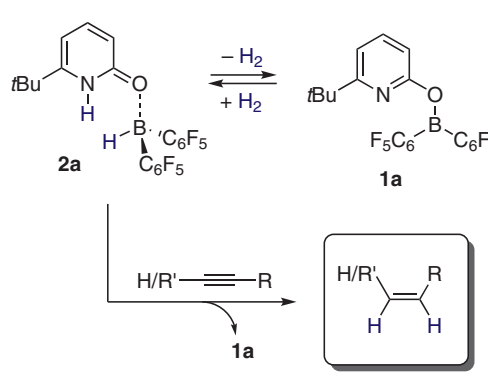

Scheme 2 Using pyridonate borane complex 1a as a catalyst for the semi-hydrogenation of alkynes and the gem-dimerization of terminal alkynes
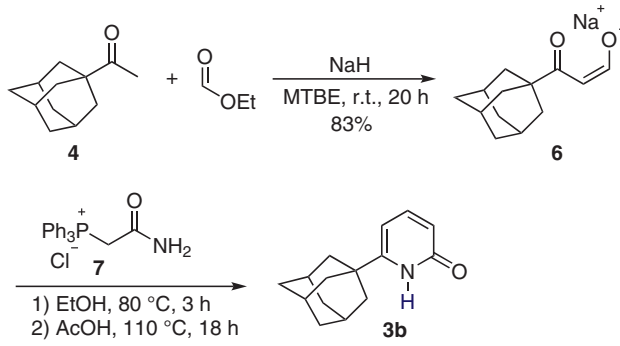

$52 \%$

Scheme 3 Synthesis of 6-adamantyl-2-pyridone $3 \mathbf{b}$ from 1-acetyladamantane (4)

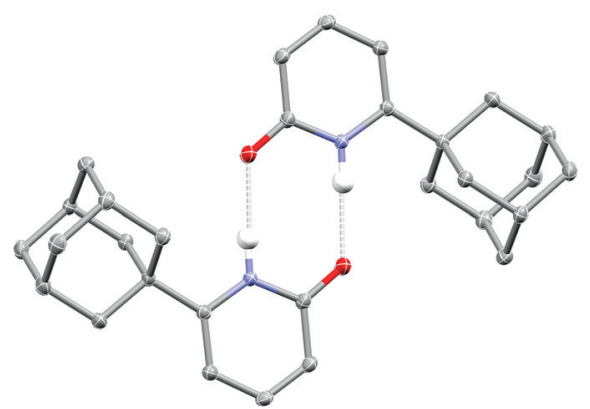

Figure 1 Molecular structure of $\mathbf{3 b}$ (CCDC 2024101) derived from SCXRD ( $50 \%$ probability ellipsoids, all hydrogens attached to carbons are omitted). ${ }^{9}$ Selected bond lengths and angles: N-C2: 1.3788(10) $\AA$, C2-O: 1.2509(10) $\AA, \mathrm{N}-\mathrm{O}: 2.8021(10) \AA, \mathrm{N}-\mathrm{H}-\mathrm{O}: 175.7(12)^{\circ}, \mathrm{N}-\mathrm{C} 2-$ O: $119.91(7)^{\circ}$.

The N-O distance is 2.8021(10) $\AA$ and thus elongated compared to that in a non-substituted 2-pyridone (2.76 $\AA$ )..$^{10}$ At the next stage, we added $\mathbf{3 b}$ to a solution of Piers' borane in benzene- $d_{6}$ (Scheme 4 ). As expected, the immediate formation of the pyridone borane complex $\mathbf{2 b}$ was observed (Figure 2). The ${ }^{1} \mathrm{H}$ NMR spectrum shows that hydrogen loss already occurs at room temperature (Figure 2, bottom). When heating the sample at $60{ }^{\circ} \mathrm{C}$ for 20 hours, full conversion of $\mathbf{2 b}$ into the pyridonate borane $\mathbf{1 b}$ was observed (Figure 2, middle). When pressurizing the reaction mixture with 2 bar of hydrogen, re-formation of $\mathbf{2} \mathbf{b}$ was observed at r.t. within 24 hours (Figure 2, top). Thus, we demonstrated that the pyridonate borane $\mathbf{1} \mathbf{b}$ is indeed capable of $\mathrm{H}_{2}$ activation. Although $\mathbf{2} \mathbf{b}$ is formed as the major product upon mixing of $\mathbf{3 b}$ and Piers' borane, a minor impurity was observed by NMR analysis (Figure 2, signals marked with asterisks). It is known that upon formation of pyridonate borane $\mathbf{1 a}$ in the presence of free 6-tert-butyl-2pyridone (3a) a bispyridone complex is formed that contains a second equivalent of the pyridone $\mathbf{3 a} .^{3}$ As described for the tert-butyl analogue, the adamantyl-derived bispyridone complex $\mathbf{8 b}$ was prepared from addition of two equivalents of $\mathbf{3 b}$ to the Piers' borane at r.t. (Scheme 5). ${ }^{11}$ After crystallization from $n$-hexane and DCM, $\mathbf{8 b}$ was isolated as colorless crystals in $84 \%$ yield. As expected, the NMR signals of $\mathbf{8 b}$ matched the signals of the impurity that had been observed during the hydrogen activation experiments. Crystallization of $\mathbf{8 b}$ enabled us to further investigate its molecular structure by SCXRD (Figure 3). Compound $\mathbf{8 b}$ crystallizes in the space group $P 2_{1} / c$. The molecular structure of $\mathbf{8 b}$ was then compared with the structure of the 6-tert-butyl2-pyridone-derived bispyridone complex 8a that was described previously. ${ }^{11}$

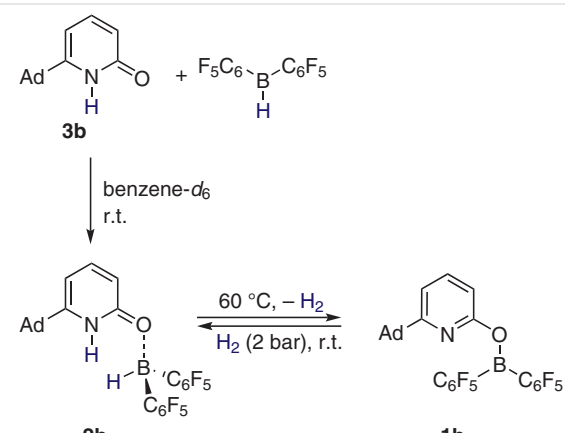

$2 b$

1b

Scheme $\mathbf{4}$ Synthesis of $\mathbf{2 b}$ and reversible hydrogen activation by $\mathbf{2 b}$ (Ad = adamantyl)

Compound 8a crystallized in the space group $C c$ and contains two independent molecules in the unit cell. Therefore, the averaged structural parameters of $\mathbf{8 a}$ are displayed (Table 1). The bispyridone complexes $8 \mathbf{a}$ and $\mathbf{8 b}$ show relat- 


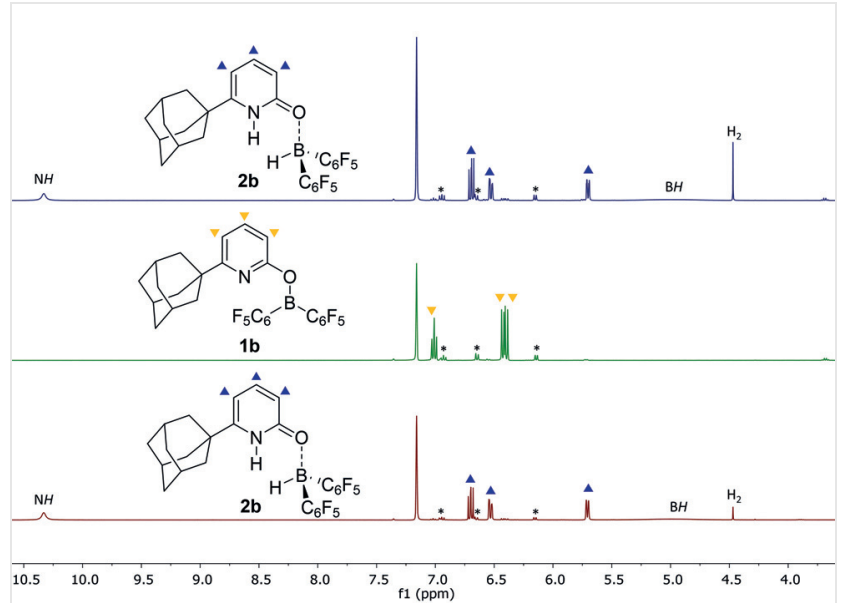

Figure $2{ }^{1} \mathrm{H}$ NMR spectrum obtained after mixing Piers' borane with $\mathbf{3 b}$ at r.t. Traces of $\mathbf{1} \mathbf{b}$ are already observable (bottom). ${ }^{1} \mathrm{H}$ NMR spectrum after heating at $60^{\circ} \mathrm{C}$ under a passive vacuum for 20 hours (middle). ${ }^{1} \mathrm{H}$ NMR spectrum after pressurizing the NMR tube with 2 bar of hydrogen and keeping the mixture at r.t. overnight $(400 \mathrm{MHz}$, benzene$d_{6}$, top).
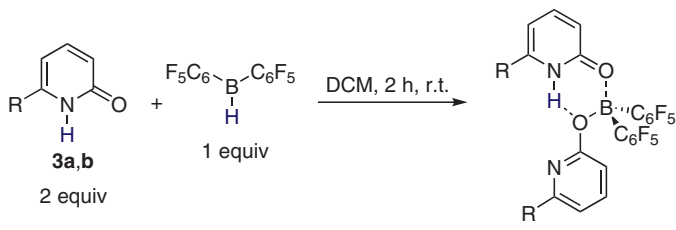

8a: $R=t B u ; 73 \%{ }^{a}$ $8 b: R=A d ; 84 \%$

Scheme 5 Synthesis of bispyridone complex $8 \mathbf{b}$ derived from 6-admantyl-2-pyridone $\mathbf{3 b}$ and Piers' borane. The 6-tert-butyl-2-pyridonederived bispyridone complex 8 a was characterized in previous work (Ad $=$ adamantyl). ${ }^{\text {a }}$ From reference 3 .

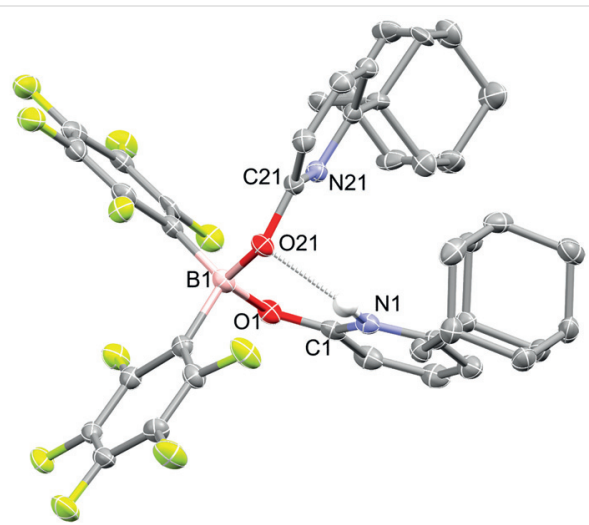

Figure 3 Molecular structure of bispyridone complex $8 \mathbf{b}$ (CCDC 2024102) derived from SCXRD (50\% probability ellipsoids, all hydrogens attached to carbons are omitted $)^{9}$ ed structural features. The bond lengths associated with the pyridone that serves as a hydrogen bond donor show little difference when comparing both structures. Interestingly, the $\mathrm{N}-\mathrm{O}$ distance associated with the hydrogen bond is slightly contracted for the adamantyl derivative $\mathbf{8 b}$ compared to the tert-butyl derivative 8a. Furthermore, the O-B-O bond angle for the tert-butyl system is widened.

Table 1 Selected Bond Lengths and Angles of $\mathbf{8 a}$ and $\mathbf{8 b}$ Derived from SCXRD

\begin{tabular}{lll}
\hline & ${\text { tert-Butyl bispyridone } 8 \mathbf{a}^{\mathrm{a}}}^{\mathrm{a}}$ & Adamantyl bispyridone 8b \\
\hline $\mathrm{N} 1-\mathrm{O} 21$ & $2.718 \AA$ & $2.697(2) \AA$ \\
$\mathrm{B} 1-\mathrm{O} 21$ & $1.471 \AA$ & $1.475(2) \AA$ \\
$\mathrm{B} 1-01$ & $1.522 \AA$ & $1.524(2) \AA$ \\
$\mathrm{C} 1-01$ & $1.292 \AA$ & $1.292(2) \AA$ \\
$\mathrm{C} 21-\mathrm{O} 21$ & $1.362 \AA$ & $1.366(2) \AA$ \\
$\mathrm{O} 1-\mathrm{B} 1-\mathrm{O} 21$ & $113.5^{\circ}$ & $112.8(1)^{\circ}$ \\
$\mathrm{O} 21-\mathrm{H} 1-\mathrm{N} 1$ & $137^{\circ}$ & $136(1)^{\circ}$ \\
$\mathrm{B} 1-\mathrm{O} 1-\mathrm{C} 1-\mathrm{N} 1$ & $3.3^{\circ}$ & $0.4(2)^{\circ}$
\end{tabular}

${ }^{a}$ Values are the average of the two independent molecules in the unit cell.

Hydrogen activation by $\mathbf{1 b}$ was further investigated computationally at the rev-DSD-PBEP86-D4/def2-QZVPP//PBEh-3c level (Figure 4). ${ }^{12,13}$ The SMD model for benzene was used to implicitly account for solvent effects (Figure 4). ${ }^{14}$ The activation barrier for hydrogen activation is $19.3 \mathrm{kcal} \mathrm{mol}^{-1}$ for the adamantyl derivative and thus 0.5 kcal mol ${ }^{-1}$ lower in Gibbs free energy compared to the 6tert-butyl pyridonate borane system. This is expected because of the more electron-rich pyridine ring of the adamantyl derivative that leads to a higher Lewis basicity. The hydrogen activation is exergonic for both derivatives by 1.4 and $1.5 \mathrm{kcal} \mathrm{mol}^{-1}$, respectively. The dissociation of the pyridone borane complexes into pyridone and Piers' borane is endergonic by $18.0 \mathrm{kcal} \mathrm{mol}^{-1}$ for the adamantyl-substituted system and $18.1 \mathrm{kcal} \mathrm{mol}^{-1}$ for the tert-butyl-substituted system, respectively. The formation of the bispyridone complex is exergonic for both systems. For the adamantylsubstituted system the gain in Gibbs free energy is almost 1 kcal mol-1 higher compared to the tert-butyl pyridone system. This might be due to the shorter and thus stronger hydrogen bond.

To gain first insights regarding the catalytic activity of $\mathbf{2 b}$, we tested it as a catalyst for the gem-selective dimerization of terminal alkynes and the hydrogenation of internal and terminal alkynes (see Scheme 2). The results for a prototypical substrate are compared to those obtained with 2a as the catalyst. ${ }^{5,7}$ The adamantyl pyridone borane complex $\mathbf{2 b}$ indeed catalyzed the gem dimerization of phenylacetylene. However, the activity of $\mathbf{2} \mathbf{b}$ was inferior compared to that of $\mathbf{2 a}$ (Scheme 6 ). The pyridone borane system $\mathbf{2 a}$ was 


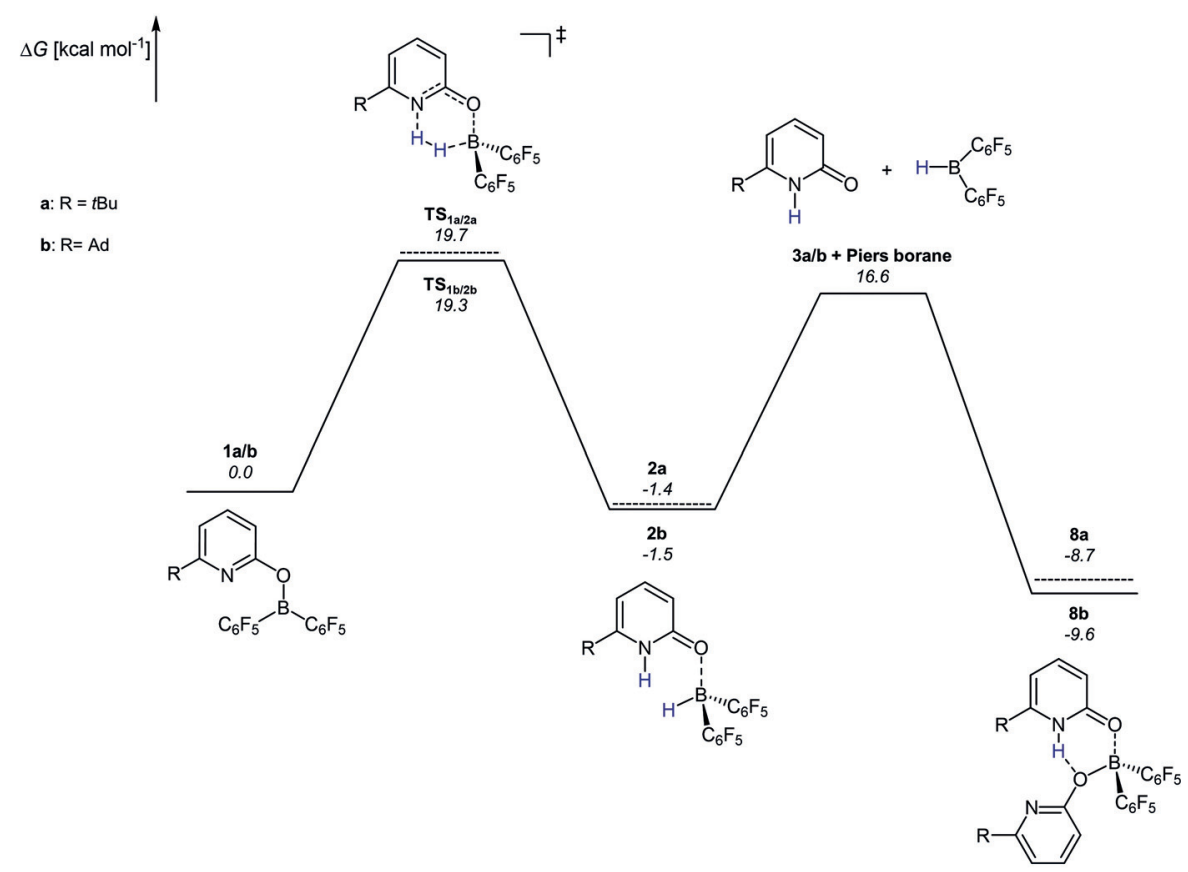

Figure 4 Gibbs free energy profile for the hydrogen activation by tert-butyl- and adamantyl-substituted pyridonate borane complexes $\mathbf{1} \mathbf{a}$ and $\mathbf{1} \mathbf{b}$ and formation of bispyridone complexes $\mathbf{7 a}$ and $\mathbf{7 b}$ computed at the revDSD-PBEP86/def2-QZVPP//PBEh-3c level of theory. Bulk solvation was considered implicitly using the SMD model for benzene.

able to hydrogenate terminal alkynes in the presence of hydrogen due to reversible $\mathrm{C}_{\mathrm{sp}}-\mathrm{H}$ activation which competes with hydrogen activation. ${ }^{5}$ Therefore, we attempted the hydrogenation of phenylacetylene using $\mathbf{2} \mathbf{b}$ as the catalyst, which gave styrene as the product in a slightly lower yield than that reported when using $\mathbf{2 a}$ (Scheme 7, top). In addition, we used $\mathbf{2 b}$ as the catalyst for the hydrogenation of 2methyl-3-pentyne (Scheme 7, bottom). The reaction gave the corresponding cis alkene exclusively after a reaction time of 16 hours in a slightly higher yield compared to that obtained with 2a.

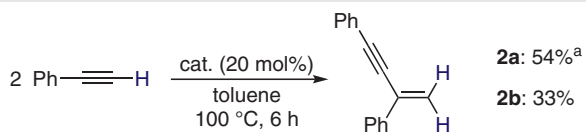

Scheme 6 Dimerization of phenylacetylene using the pyridone borane complexes $\mathbf{2} \mathbf{a}$ and $\mathbf{2} \mathbf{b}$ as catalysts under previously reported optimized conditions. ${ }^{7}$ The reported yields are the average of two runs. ${ }^{a}$ From reference 7 .

In summary, we have synthesized the novel 6-adamantyl-2-pyridone $\mathbf{3 b}$ from commercially available 1-acetyladamantane in $44 \%$ yield over two steps. This pyridone derivative can form pyridonate borane complex $\mathbf{1 b}$ on loss of hydrogen. The pyridonate borane $\mathbf{1 b}$ can reactivate hydrogen

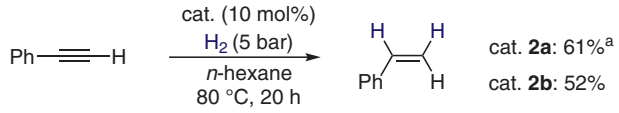

$$
\begin{aligned}
& \rangle=\frac{\begin{array}{c}
\text { cat. }(5 \mathrm{~mol} \%) \\
\mathrm{H}_{2}(5 \mathrm{bar}) \\
n \text {-hexane } \\
80^{\circ} \mathrm{C}, 16 \mathrm{~h}
\end{array}}{\text { cat. } 2 \mathrm{~b}: 88 \%}
\end{aligned}
$$

Scheme 7 Hydrogenation of phenylacetylene and 2-methyl-3-pentyne using the pyridone borane complexes $\mathbf{2 a}$ and $\mathbf{2} \mathbf{b}$ under previously reported optimized conditions. ${ }^{5}$ Note that for the formation of the respective pyridone borane complex, a slight excess of Piers' borane was used ( 1.3 equiv). The reported yields are the average of two runs. ${ }^{\text {a }}$ From reference 5 .

at room temperature under 2 bar of hydrogen. We were also able to synthesize a bispyridone complex $\mathbf{8 b}$ that is an adduct of pyridonate borane complex $\mathbf{1} \mathbf{b}$ with another equivalent of pyridone. The molecular structure of $\mathbf{8 b}$, derived from SCXRD, revealed a shortened hydrogen bond compared to the tert-butyl-derived bispyridone complex that was described previously. ${ }^{11}$ Additionally, we have shown that $\mathbf{3 b}$ in conjunction with Piers' borane is a suitable catalyst for the gem dimerization of terminal alkynes and the hydrogenation of terminal and internal alkynes. 
All manipulations involving air- or moisture-sensitive compounds were performed using standard Schlenk or glovebox techniques. All dry, non-deuterated solvents were, if commercially available, purchased from Acros Organics or Sigma-Aldrich in sealed bottles with a septum. Deuterated solvents were distilled under inert conditions and kept in a glovebox over $4 \AA$ molecular sieves or were degassed using the freeze/pump/thaw method and stored over $4 \AA$ molecular sieves for at least one day prior to use. $\mathrm{B}\left(\mathrm{C}_{6} \mathrm{~F}_{5}\right)_{3}$ was synthesized from boron trifluoride-diethyl etherate according to a literature procedure. ${ }^{15}$ Piers' borane was synthesized from $\mathrm{B}\left(\mathrm{C}_{6} \mathrm{~F}_{5}\right)_{3}$ according to a modified literature procedure: ${ }^{16} \mathrm{~B}\left(\mathrm{C}_{6} \mathrm{~F}_{5}\right)_{3}(2.0 \mathrm{~g}, 3.9 \mathrm{mmol})$ and $\mathrm{Et}_{3} \mathrm{SiH}$ $(623 \mu \mathrm{L}, 3.9 \mathrm{mmol})$ were dissolved in benzene $(20 \mathrm{~mL})$ in a pressure tube and stirred for $4-5 \mathrm{~d}$ at $60{ }^{\circ} \mathrm{C}$. The reaction mixture was cooled to r.t., causing precipitation of the product. The supernatant was removed, and the residue was washed with benzene $(3 \times 3 \mathrm{~mL})$ and $n$ pentane $(2 \times 2-3 \mathrm{~mL})$. 2-Triphenylphosphonium-acetamide chloride was synthesized according to a literature procedure. ${ }^{8}$ Flash column chromatography was performed using Macherey-Nagel silica gel $(0.04-0.063 \mathrm{~mm})$. TLC analyses were performed using standard silica TLC plates purchased from Macherey-Nagel. Melting points were measured on an A. Krüss Optotronics melting point meter. IR spectra were recorded on a Bruker Optics VERTEX70 Platinum ATR spectrometer. NMR spectra were recorded on Bruker Avance II $200 \mathrm{MHz}$, Bruker Avance III HD $400 \mathrm{MHz}$, Bruker Avance II $400 \mathrm{MHz}$ or Bruker Avance III HD $600 \mathrm{MHz}$ spectrometers. ${ }^{1} \mathrm{H}$ and ${ }^{13} \mathrm{C}$ NMR chemical shifts are referenced to residual solvent resonance signals. Mass spectra were recorded on an ESI-MS Bruker Micro-TOF mass spectrometer. Samples were dissolved in methanol. In positive ion detection mode the capillary current was set to $4500 \mathrm{~V}$ with an end plate offset of $-500 \mathrm{~V}$, and in negative mode the capillary current was set to 3000 $\mathrm{V}$ with an end plate offset of $500 \mathrm{~V}$. Elemental analysis was performed with a Thermo FlashEA 1112 instrument.

\section{Sodium Enolate 6}

Sodium hydride (60\% dispersion, $0.84 \mathrm{~g}, 21 \mathrm{mmol}$ ) was suspended in MTBE $(15 \mathrm{~mL})$. EtOH $(0.1 \mathrm{~mL})$ was added slowly with gas evolution at r.t. Next, a solution of ethyl formate $(1.37 \mathrm{~g}, 18.5 \mathrm{mmol})$ and 1-acetyladamantane (4) (2.99 g, $16.8 \mathrm{mmol})$ in MTBE $(5.0 \mathrm{~mL})$ was added dropwise over $2 \mathrm{~h}$. The resulting yellow slurry was diluted with MTBE $(5 \mathrm{~mL})$ and the suspension was stirred overnight at r.t. The mixture was filtered, and the yellow residue was washed multiple times with $n$-pentane. After drying in vacuo, the product was obtained as a pale yellow solid (3.2 g, 83\%). No NMR data were obtained because of the insolubility of the product. The product was used without further purification.

IR (ATR): 2892, 2850, 1698, 1586, 1446, 1360, 1224, $774 \mathrm{~cm}^{-1}$.

HRMS (ESI): $m / z$ [M - Na] $]^{-}$calcd for $\mathrm{C}_{13} \mathrm{H}_{17} \mathrm{O}_{2}$ : 205.1234; found: 205.1233.

\section{6-Adamantyl-2-pyridone (3b)}

Sodium enolate $\mathbf{6}$ (1.07 g, $5.00 \mathrm{mmol}$ ) was suspended in EtOH (25 $\mathrm{mL}$ ). 2-Triphenylphosphonium-acetamide chloride (7) (1.78 g, 5.00 mmol) was added and the mixture was heated at $80^{\circ} \mathrm{C}$ for $3 \mathrm{~h}$. Acetic acid $(10 \mathrm{~mL})$ was then added and the mixture was refluxed at $110{ }^{\circ} \mathrm{C}$ for $18 \mathrm{~h}$. The solvent was then removed and the residual acetic acid was co-evaporated with toluene. The product was purified by column chromatography on silica gel using $n$-hexane/EtOAc/AcOH (3:1:0.01). The product was isolated as a white crystalline solid (600 mg, 52\%).
$R_{f}=0.24 ; \mathrm{mp} 219.5^{\circ} \mathrm{C}$

${ }^{1} \mathrm{H}$ NMR $\left(400 \mathrm{MHz}, \mathrm{CDCl}_{3}\right): \delta=11.1(\mathrm{~s}, 1 \mathrm{H}, \mathrm{NH}), 7.36(\mathrm{dd}, J=9.1 \mathrm{~Hz}$, $7.1 \mathrm{~Hz} 1 \mathrm{H}, \operatorname{Pyr} H$ ), 6.38 (dd, $J=9.1 \mathrm{~Hz}, 0.8 \mathrm{~Hz}, 1 \mathrm{H}, \operatorname{Pyr} H$ ), 6.03 (dd, $J=$ $7.0 \mathrm{~Hz}, 0.7 \mathrm{~Hz}, 1 \mathrm{H}, \operatorname{Pyr} H), 2.13-2.08(\mathrm{~m}, 3 \mathrm{H}), 1.96-1.88(\mathrm{~m}, 6 \mathrm{H})$, $1.79-1.71(\mathrm{~m}, 6 \mathrm{H})$.

${ }^{13} \mathrm{C}$ NMR $\left(100 \mathrm{MHz}, \mathrm{CDCl}_{3}\right): \delta=164.9\left(\mathrm{C}_{\mathrm{q}}\right), 157.1\left(\mathrm{C}_{\mathrm{q}}\right), 141.6(\mathrm{Pyr}-\mathrm{CH})$, 117.6 (Pyr-CH), 101.6 (Pyr-CH), $40.6\left(3 \mathrm{CH}_{2}\right), 36.6\left(\mathrm{C}_{\mathrm{q}}\right), 36.4\left(3 \mathrm{CH}_{2}\right)$, $28.2(3 \mathrm{CH})$.

HRMS (ESI): $m / z[M+N a]^{+}$calcd for $\mathrm{C}_{15} \mathrm{H}_{19} \mathrm{NONa:} 252.1358$; found: 252.1360.

Anal. Calcd for $\mathrm{C}_{15} \mathrm{H}_{19} \mathrm{NO}$ : C, 78.56; $\mathrm{H}, 8.35$; N, 6.11. Found: C, 78.18; H, 8.08; N 6.11.

\section{6-Adamantyl-2-pyridone Borane Complex 2b}

In a nitrogen-filled glovebox, 6-adamantyl-2-pyridone (3b) $6.8 \mathrm{mg}$, $0.03 \mathrm{mmol}$ ) and Piers' borane ( $10.6 \mathrm{mg}, 0.031 \mathrm{mmol}$ ) were dissolved in benzene- $d_{6}(0.3 \mathrm{~mL})$ in a vial. The solution was transferred to an NMR tube via a J. Young valve and the vial was washed with benzene$d_{6}(0.1 \mathrm{~mL})$. NMR spectra were recorded immediately, showing the formation of pyridone borane complex $\mathbf{2 b}$ and bispyridone complex 8 b.

${ }^{1} \mathrm{H}$ NMR (400 MHz, benzene- $\left.d_{6}\right): \delta=10.33(\mathrm{~s}, 1 \mathrm{H}, \mathrm{NH}), 6.69(\mathrm{dd}, J=$ $8.9 \mathrm{~Hz}, 7.5 \mathrm{~Hz}, 1 \mathrm{H}, \mathrm{Pyr}-H$ ), 6.53 (ddd, J = 8.9 Hz, $2.2 \mathrm{~Hz}, 0.9 \mathrm{~Hz}, 1 \mathrm{H}$, Pyr- $H$ ), 5.70 (ddd, $J=7.5 \mathrm{~Hz}, 1.9 \mathrm{~Hz}, 1.0 \mathrm{~Hz}, 1 \mathrm{H}, \mathrm{Pyr}-H$ ), 5.01 (br s, $1 \mathrm{H}$, $\mathrm{BH}), 1.66-1.59(\mathrm{~m}, 3 \mathrm{H}, \mathrm{CH}), 1.43-1.35\left(\mathrm{~m}, 3 \mathrm{H}, \mathrm{CH}_{2}\right), 1.30-1.21(\mathrm{~m}, 3$ $\left.\mathrm{H}, \mathrm{CH}_{2}\right), 1.15-1.09\left(\mathrm{~m}, 6 \mathrm{H}, \mathrm{CH}_{2}\right)$.

${ }^{13} \mathrm{C}$ NMR $\left(100 \mathrm{MHz}\right.$, benzene- $\left.d_{6}\right): \delta=161.9\left(\mathrm{C}_{\mathrm{q}}\right), 156.9\left(\mathrm{C}_{\mathrm{q}}\right), 145.8(\mathrm{Pyr}-$ $\mathrm{CH}), 114.3$ (Pyr-CH), $109.4(\mathrm{Pyr}-\mathrm{CH}), 40.1\left(\mathrm{CH}_{2}\right), 36.7\left(\mathrm{C}_{\mathrm{q}}\right), 35.7\left(\mathrm{CH}_{2}\right)$, $28.0(\mathrm{CH})$.

${ }^{11} \mathrm{~B}$ NMR $\left(128 \mathrm{MHz}\right.$, benzene- $\left.d_{6}\right): \delta=-7.1$.

${ }^{19} \mathrm{~F}$ NMR (377 MHz, benzene- $\left.d_{6}\right): \delta=-134.4(\mathrm{dd}, J=22.1 \mathrm{~Hz}, 7.7 \mathrm{~Hz})$, $-158.6(\mathrm{t}, J=20.5 \mathrm{~Hz}),-164.3(\mathrm{ddd}, J=24.3 \mathrm{~Hz}, 19.8 \mathrm{~Hz}, 9.4 \mathrm{~Hz})$ (F integration 2:1:2).

\section{6-Adamantyl-2-pyridonate Borane Complex 1b}

In a nitrogen-filled glovebox, 6-adamantyl-2-pyridone (3b) $6.8 \mathrm{mg}$, $0.03 \mathrm{mmol}$ ) and Piers' borane $(10.8 \mathrm{mg}, 0.031 \mathrm{mmol})$ were dissolved in benzene- $d_{6}(0.4 \mathrm{~mL})$ in a vial. The solution was transferred to an NMR tube via a J. Young valve and the vial was washed with benzene$d_{6}(0.1 \mathrm{~mL})$. The NMR tube was degassed three times using the freeze/pump/thaw technique and placed in a $60{ }^{\circ} \mathrm{C}$ oil bath for $20 \mathrm{~h}$. Afterwards, it was again degassed via freeze/pump/thaw and NMR spectra were recorded. The formation of pyridonate borane $\mathbf{1 b}$ and bispyridone complex $\mathbf{8 b}$ were observed.

${ }^{1} \mathrm{H}$ NMR $\left(400 \mathrm{MHz}\right.$, benzene- $\left.d_{6}\right): \delta=7.01(\mathrm{t}, J=8.0 \mathrm{~Hz}, 1 \mathrm{H}, \mathrm{Pyr}-H)$, $6.43(\mathrm{dd}, J=7.7 \mathrm{~Hz}, 0.4 \mathrm{~Hz}, 1 \mathrm{H}, \mathrm{Pyr}-H), 6.40(\mathrm{dd}, J=8.2 \mathrm{~Hz}, 0.6 \mathrm{~Hz}, 1 \mathrm{H}$, Pyr-H) 1.85-1.78 (m, $3 \mathrm{H}, \mathrm{CH}), 1.60-1.44\left(\mathrm{~m}, 12 \mathrm{H}, \mathrm{CH}_{2}\right)$.

${ }^{13} \mathrm{C}$ NMR $\left(100 \mathrm{MHz}\right.$, benzene- $\left.d_{6}\right): \delta=166.6\left(\mathrm{C}_{\mathrm{q}}\right), 163.4\left(\mathrm{C}_{\mathrm{q}}\right), 142.4(\mathrm{Pyr}-$ C), $114.5($ Pyr- $C), 108.2(\operatorname{Pyr}-C), 41.2\left(\mathrm{CH}_{2}\right), 38.7\left(\mathrm{C}_{\mathrm{q}}\right), 36.6\left(\mathrm{CH}_{2}\right), 28.7$ $(\mathrm{CH})$.

${ }^{11} \mathrm{~B}$ NMR $\left(128 \mathrm{MHz}\right.$, benzene- $\left.d_{6}\right): \delta=29.7$.

${ }^{19} \mathrm{~F}$ NMR (377 MHz, benzene- $\left.d_{6}\right): \delta=-132.3(\mathrm{dd}, J=24.0,9.2 \mathrm{~Hz}$ ), -150.8 (s), -162.0 to -162.1 (m) (F integration 2:1:2). 


\section{Adamantyl Bispyridone Complex 8b}

In a nitrogen-filled glovebox, 6-adamantyl-2-pyridone (3b) $(22.9 \mathrm{mg}$, $0.1 \mathrm{mmol}$ ) and Piers' borane $(17.3 \mathrm{mg}, 0.05 \mathrm{~mol}$ ) were suspended in DCM $(0.7 \mathrm{~mL})$. The solution was stirred for $2 \mathrm{~h}$ at r.t. and then $n$-hexane $(5 \mathrm{~mL})$ was added. Upon evaporation of the DCM, the product crystallized as colorless crystals ( $33.7 \mathrm{mg}, 84 \%$ ).

${ }^{1} \mathrm{H}$ NMR (400 MHz, benzene- $d_{6}$ ): $\delta=12.8(\mathrm{~s}, 1 \mathrm{H}, \mathrm{NH}$ ), 6.93 (dd, $J=8.4$ $\mathrm{Hz}, 7.6 \mathrm{~Hz}, 2 \mathrm{H}, \operatorname{Pyr} H$ ), 6.65 (d, J = 8.4 Hz, $2 \mathrm{H}, \operatorname{Pyr} H$ ), 6.14 (d, $J=7.5 \mathrm{~Hz}$, $2 \mathrm{H}, \mathrm{PyrH}$ ), 1.83 (s, $6 \mathrm{H}, 6 \mathrm{CH}$ ), 1.58-1.49 (m, $24 \mathrm{H}, 12 \mathrm{CH}_{2}$ ).

${ }^{13} \mathrm{C}$ NMR $\left(100 \mathrm{MHz}\right.$, benzene- $\left.d_{6}\right): \delta=162.6\left(\mathrm{C}_{\mathrm{q}}\right), 162.5\left(\mathrm{C}_{\mathrm{q}}\right), 142.2(\mathrm{Pyr}-$ $\mathrm{CH}), 113.6$ (Pyr-CH), 110.9 (Pyr-CH), $40.9\left(\mathrm{CH}_{2}\right), 37.9\left(\mathrm{C}_{\mathrm{q}}\right), 36.5\left(\mathrm{CH}_{2}\right)$ $28.6(\mathrm{CH})$.

${ }^{11} \mathrm{~B}$ NMR $\left(128 \mathrm{MHz}\right.$, benzene- $\left.d_{6}\right): \delta=4.93$.

${ }^{19} \mathrm{~F}$ NMR (377 MHz, benzene- $\left.d_{6}\right): \delta=-137.1$ (dd, $J=24.4,9.3 \mathrm{~Hz}$ ), $-158.1(\mathrm{t}, J=20.6 \mathrm{~Hz}),-164.5$ to $-164.7(\mathrm{~m})$ (F integration 2:1:2).

\section{Catalytic Experiments}

\section{Dimerization of Phenylacetylene}

The gem dimerization was performed according to a previously reported procedure. ${ }^{7}$ Under a nitrogen atmosphere, 6-adamantyl-2pyridone (3b) ( $7.0 \mathrm{mg}, 0.03 \mathrm{mmol}$ ) and Piers' borane $(11.5 \mathrm{mg}, 0.033$ $\mathrm{mmol})$ were dissolved in toluene $(1 \mathrm{~mL})$. The solution was transferred to a Schlenk tube and phenylacetylene $(16.5 \mu \mathrm{L}, 0.15 \mathrm{mmol})$ was added. The tube was placed in a pre-heated oil bath at $100{ }^{\circ} \mathrm{C}$ and the contents stirred for $6 \mathrm{~h}$. The solvent was removed in vacuo and trimethoxybenzene $(8.4 \mathrm{mg}, 0.05 \mathrm{mmol})$ was added. The residue was dissolved in chloroform- $d$ and NMR spectra were recorded (see Figures SI 29 and SI 30 in the Supporting Information).

\section{Hydrogenation of Alkynes}

The hydrogenations were performed according to a previously reported procedure. ${ }^{5}$ Under a nitrogen atmosphere, 6-adamantyl-2pyridone (3b) ( $6.9 \mathrm{mg}, 0.03 \mathrm{mmol}$ ) and Piers' borane ( $13.5 \mathrm{mg}, 0.039$ $\mathrm{mmol}$ ) were dissolved in $n$-hexane $(5 \mathrm{~mL})$ in a Fisher-Porter type reactor bomb. The respective alkyne [phenylacetylene $(0.3 \mathrm{mmol})$ or 2methyl-3-pentyne $(0.6 \mathrm{mmol}]$ was added and the vessel sealed. It was then connected to a $\mathrm{H}_{2}$ bomb cylinder with a gas hose that had been rinsed several times with hydrogen. The vessel was pressurized with 5 bar hydrogen and placed in an $80{ }^{\circ} \mathrm{C}$ pre-heated oil bath for $20 \mathrm{~h}$ or $16 \mathrm{~h}$. Finally, trimethoxybenzene $(8.4 \mathrm{mg}, 0.05 \mathrm{mmol})$ was added and NMR spectra were recorded (see Figures SI 25-28 in the Supporting Information).

\section{Funding Information}

This work was supported by the Deutsche Forschungsgemeinschaft (DFG; German Research Foundation) (GE 3117/1-1).

\section{Acknowledgment}

Continued support from Prof. Dr. P. R. Schreiner, Prof. Dr. R. Göttlich, and Prof. Dr. H. A. Wegner is acknowledged.

\section{Supporting Information}

Supporting information for this article is available online at https://doi.org/10.1055/s-0040-1705970.

\section{References}

(1) Welch, G. C.; San Juan, R. R.; Masuda, J. D.; Stephan, D. W. Science 2006, 314, 1124.

(2) (a) Stephan, D. W. J. Am. Chem. Soc. 2015, 137, 10018. (b) Stephan, D. W.; Erker, G. Angew. Chem. Int. Ed. 2015, 54, 6400.

(3) Gellrich, U. Angew. Chem. Int. Ed. 2018, 57, 4779.

(4) (a) Gunanathan, C.; Milstein, D. Acc. Chem. Res. 2011, 44, 588. (b) Khusnutdinova, J. R.; Milstein, D. Angew. Chem. Int. Ed. 2015, 54, 12236. (c) Gellrich, U.; Diskin-Posner, Y.; Shimon, L. J. W.; Milstein, D. J. Am. Chem. Soc. 2016, 138, 13307.

(5) Wech, F.; Hasenbeck, M.; Gellrich, U. Chem. Eur. J. 2020, 26, 13445.

(6) (a) Dureen, M. A.; Stephan, D. W. J. Am. Chem. Soc. 2009, 131, 8396. (b) Chen, C.; Eweiner, F.; Wibbeling, B.; Fröhlich, R.; Senda, S.; Ohki, Y.; Tatsumi, K.; Grimme, S.; Kehr, G.; Erker, G. Chem. Asian J. 2010, 5, 2199.

(7) Hasenbeck, M.; Müller, T.; Gellrich, U. Catal. Sci. Technol. 2019, 9, 2438.

(8) Hintermann, L.; Dang, T. T.; Labonne, A.; Kribber, T.; Xiao, L.; Naumov, P. Chem. Eur. J. 2009, 15, 7167.

(9) CCDC 2024101 and CCDC 2024102 contain the supplementary crystallographic data for this paper. The data can be obtained free of charge from The Cambridge Crystallographic Data Centre via www.ccdc.cam.ac.uk/getstructures.

(10) Yang, H. W.; Craven, B. M. Acta Crystallogr., Sect. B 1998, 54, 912.

(11) Müller, T.; Hasenbeck, M.; Becker, J.; Gellrich, U. Eur. J. Org. Chem. 2019, 451.

(12) (a) Hellweg, A.; Hättig, C.; Höfener, S.; Klopper, W. Theor. Chem. Acc. 2007, 117, 587. (b) Caldeweyher, E.; Bannwarth, C.; Grimme, S. J. Chem. Phys. 2017, 147, 34112. (c) Caldeweyher, E.; Ehlert, S.; Hansen, A.; Neugebauer, H.; Spicher, S.; Bannwarth, C.; Grimme, S. J. Chem. Phys. 2019, 150, 154122. (d) Weigend, F. Phys. Chem. Chem. Phys. 2006, 8, 1057. (e) Santra, G.; Sylvetsky, N.; Martin, J. M. L. J. Phys. Chem. A 2019, 123, 5129. (f) Weigend, F.; Ahlrichs, R. Phys. Chem. Chem. Phys. 2005, 7, 3297.

(13) (a) Kruse, H.; Grimme, S. J. Chem. Phys. 2012, 136, 154101. (b) Grimme, S.; Brandenburg, J. G.; Bannwarth, C.; Hansen, A. J. Chem. Phys. 2015, 143, 54107. (c) Grimme, S.; Antony, J.; Ehrlich, S.; Krieg, H. J. Chem. Phys. 2010, 132, 154104. (d) Grimme, S.; Ehrlich, S.; Goerigk, L. J. Comput. Chem. 2011, 32, 1456. (e) Weigend, F. J. Comput. Chem. 2008, 29, 167.

(14) Marenich, A. V.; Cramer, C. J.; Truhlar, D. G. J. Phys. Chem. B 2009, 113, 6378.

(15) Soltani, Y.; Wilkins, L. C.; Melen, R. L. Angew. Chem. Int. Ed. 2017, $56,11995$.

(16) Longobardi, L. E.; Johnstone, T. C.; Falconer, R. L.; Russell, C. A.; Stephan, D. W. Chem. Eur. J. 2016, 22, 12665. 